\title{
The propagation of seafloor spreading in the southwestern subbasin, South China Sea
}

\author{
LI JiaBiao $^{1,2 *}$, DING WeiWei ${ }^{1,2}$, WU ZiYin ${ }^{1,2}$, ZHANG Jie ${ }^{1,2} \&$ DONG ChongZhi ${ }^{1,2}$ \\ ${ }^{1}$ Second Institute of Oceanography, State Oceanic Administration, Hangzhou 310012, China; \\ ${ }^{2}$ Key Laboratory of Submarine Geosciences, State Oceanography Administration, Hangzhou 310012, China
}

Received November 20, 2011; accepted April 28, 2012

\begin{abstract}
On the basis of the summary of basic characteristics of propagation, the dynamic model of the tectonic evolution in the Southwestern Subbasin (SWSB), South China Sea (SCS), has been established through high resolution multi-beam swatch bathymetry and multi-channel seismic profiles, combined with magnetic anomaly analysis. Spreading propagates from NE to SW and shows a transition from steady seafloor spreading, to initial seafloor spreading, and to continental rifting in the southwest end. The spreading in SWSB (SCS) is tectonic dominated, with a series of phenomena of inhomogeneous tectonics and sedimentation.
\end{abstract}

Southwestern Subbasin, South China Sea, propagation of seafloor spreading, morphotectonics, tectonic divisions, dynamic mechanism

Citation: $\quad$ Li J B, Ding W W, Wu Z Y, et al. The propagation of seafloor spreading in the southwestern subbasin, South China Sea. Chin Sci Bull, 2012, 57: 3182-3191, doi: 10.1007/s11434-012-5329-2

Recent studies on continental rifting and oceanic spreading point out that not all the rifting and spreading occur synchronously along strike [1], and propagating spreading of oceanic ridges and sea basins has gradually attracted more attention. Ridge propagation means the spreading center of the oceanic ridge or the sea basin does not spread concurrently, however it propagates along a certain direction with different velocities. During this ridge propagation, there may be a pause.

Although there is no framework to systematically summarize propagation in the ocean and marginal seas, its worldwide distribution is gradually known by people. Fumes et al. [2] considered that propagating rifts were common features along intermediate- to fast-spreading modern mid-ocean ridges and back-arc spreading centers (e.g. the East Pacific Rise (EPR); the Mid-Indian Ridge (MIR) and the Southeast Indian Ridge (SEIR) [3-8]. On the basis of publications over recent years, propagating rifting and spreading also occur at modern slow-spreading mid-ocean ridges and back-arc spreading centers (e.g. the

*Corresponding author (email: jbli@ sio.org.cn)
Mid-Atlantic Ridge (MAR) [9], but there is no evidence for propagating spreading at ultra-slow spreading mid-ocean ridges (e.g. the Southwest Indian Ridge (SWIR)). In addition to mid-ocean ridges, marginal basins usually have more common and typical characteristics for the evolution of ridge propagation, and become examples and heated topics in the research of propagating spreading.

With respect to mid-ocean ridges, ridge propagation is mainly concentrated in the Pacific Ocean, the Indian Ocean, and the Southern Ocean. The east Pacific Rise $\left(2^{\circ} \mathrm{S}-20^{\circ} \mathrm{N}\right.$, $26^{\circ}-32^{\circ} \mathrm{S}$ ) has a history of propagation from south to north as a whole $[3,4]$. The propagation rate of the East Pacific Rise $\left(26^{\circ}-32^{\circ} \mathrm{S}\right)$ is $120 \mathrm{~mm} / \mathrm{a}$ on average, and was calculated as $150 \mathrm{~mm} / \mathrm{a}$ since 1.9 Ma by Acton et al. [5]. The Juan de Fuca Ridge, located in the eastern Pacific Ocean, is a northward propagating spreading ridge [6] with a propagation rate of $44 \mathrm{~m} / \mathrm{a}$ [7]. The Galapagos Ridge, along the equator in the eastern Pacific, also has characteristics of westward propagation; moreover, it is propagating into oceanic crust formed by the spreading of the East Pacific Rise, with a propagation rate of $55.5-58.5 \mathrm{~mm} / \mathrm{a}$ [5]. The Chile Ridge, located at the joint of the Pacific Plate, Antarc- 
tic Plate, and Nazca Plate, propagates northward with a propagation rate of $60 \mathrm{~mm} / \mathrm{a}$ [8]. The Pacific-Antarctic Ridge, with ENE oriented propagation, has a propagation rate of $12-38 \mathrm{~mm} / \mathrm{a}$ [5].

The Carlsberg Ridge in the Indian Ocean and the Southeast Indian Ridge are propagating spreading ridges. The Southeast Indian Ridge propagates from WNW to ESE, but there is a big difference in propagation rate $(7-49 \mathrm{~mm} / \mathrm{a})$. In the Atlantic Ocean, only the regions north of Iceland $\left(34^{\circ}-46^{\circ} \mathrm{S} ; 75^{\circ}-98^{\circ} \mathrm{W}\right)$ and south of $30^{\circ} \mathrm{S}$ show southwestward propagation, but each part has its own propagation direction and rate [5,9].

Propagating spreading basins are mainly concentrated in the Pacific Ocean, and usually locate near continental margins and island arcs. The research results of Okino et al. [10] show that the Parece Vela Basin had an east-west opening with northward propagation, together with the Shikoku Basin, and the process of propagating spreading of these two basins formed the back-arc basin just behind the Izu-Bonin (Ogasawara)/Mariana arc. The Woodlark Basin is undergoing westward propagation [11-13], and we can observe both the rifting of the continental crust and the spreading of the oceanic crust. The Lau Basin is between a volcanic and nonvolcanic arc. According to geophysical data, two spreading centers are identified in the basin, which are the results of ridge propagation from northeast to southwest [14].

The Gulf of Aden, which is a typical propagating spreading marginal basin, is the result of rifting between the Arabian and African plates. It is a V-shaped basin with a $1500 \mathrm{~km}$ spreading ridge. On the basis of magnetic anomalies, the Aden Ridge has been propagatied westward since 17.5 Ma (Magnetic anomaly 5d), and it is still undergoing active seafloor spreading. The Gulf of Aden can be divided from east to west into three different provinces, separated by major discontinuities. The crust of the eastern ridge $\left(58^{\circ}-52^{\circ} \mathrm{E}\right)$ and the central ridge $\left(52^{\circ}-45^{\circ} \mathrm{E}\right)$ displays oceanic character, while the western ridge $\left(45^{\circ}-43^{\circ} \mathrm{E}\right)$ transitions from sea floor spreading to continental rifting, with a magnetic quiet zone in the west part of it [15]. The propagating spreading rate and direction of the Aden Ridge varies along the axial direction, which reflects that the tectonic dynamics of spreading in marginal basins are unstable.

The SCS is a unique marginal sea of the Western Pacific Ocean in the research of tectonic evolution. Although the dispute over formation age still exists, the deep sea basin in SCS has oceanic nature, which is generally wide to the east and narrow to the west, and is considered to be the result of Cenozoic sea floor spreading [16-19]. According to different structural characteristics, the SCS could be further divided into three subbasins: the East Subbasin (ESB), Southwest Subbasin (SWSB), and Northwest Subbasin (NWSB). SWSB is also a V-shaped basin with a clear NE-SW spreading ridge, and interacts with the western margin fault to the west. Does that mean the SWSB has a similar tectonic evolution history of ridge propagation as the
Gulf of Aden? The SWSB is an important basin in the SCS. Because of the relative weakness in investigation and data accumulation, and the complexity of the tectonic evolution, tectonic research has not made substantive progress there for a long time. In this paper, new research on the dynamic model of the tectonic evolution in the SWSB of the SCS has been established based on new high resolution geophysical data from a ridge propagation angle, which is expected to promote the understanding of tectonic evolution and propose a new example of ridge propagation in marginal basins. The result will also enhance the level of understanding of tectonic evolution in the SCS, and bring new limits and research approaches to the contentious problems existing in it.

\section{Geological background}

The South China Sea, located at the convergence of three major plates (the Eurasian, Pacific, and Indo-Australian Plates), is considered to be a key site and natural laboratory for studying the conversation mechanism of basin dynamics. During the Cenozoic the SCS experienced continental rifting and subsequently seafloor spreading, and then oceanic crust subduction to the east and collision to the south. All three types of continental margins surround the SCS, that is, passive margins (rifting) in the north and south, an active margin (subduction) in the east, and a transform margin in the west, which is the integrated result of a complex tectonic evolution history.

As a result of the lack of drilling data, the tectonic evolution history of SCS is mainly established on the analysis of magnetic anomalies. The ESB has reached a relatively common understanding with respect to the pattern of spreading and formation age. The early work of Taylor and Hayes [16] in the ESB has been generally accepted. They identified magnetic anomaly $\mathrm{C} 11-\mathrm{C} 5 \mathrm{~d}$ from the margins to the center and the magnetic anomalies distributed symmetrically on both sides of the relic spreading ridge, which is now occupied by the Huangyan Seamount Chain. Briais et al. [18] verified this through detailed analyses of magnetic data and suggested a 30 to 16 Ma spreading scenario according to the revised geomagnetic polarity timescale by Candes and Kent [20]. Different scientists have different conclusions about the spreading history of the SWSB. The mainstream research in this field includes the work of Taylor and Hayes [17] who interpreted magnetic anomalies C6b-C5c in the SWSB, and pointed out that the SWSB was opened between 23 and 16 Ma with NW-SE spreading. Yao et al. [19] identified one more deformed sequence in the SWSB by correlating seismic profiles through the ESB and SWSB, and believed that the SWSB opening should be much older, 42-35 Ma. Much earlier spreading of 70-63 Ma (magnetic anomalies M 32-27) was proposed by Ru and Pigott [21] according to water depth and heat flow, the same as the result obtained by Lue [22] based on magnetic anom- 
alies. Multiple solutions of spreading age in the SWSB result from its existing contradictions (such as deep water depth with high heat flow, etc.) as well as the poor accuracy of the magnetic survey data and low survey-grid density obtained at that time, which affect the extraction of characteristics and knowledge of the spatial continuity of magnetic anomalies.

The dynamic models of the tectonic evolution in the SWSB fall into two groups: (1) Briais et al. [18] proposed that the SWSB and the ESB began to spread in a N-S orientation at $30 \mathrm{Ma}$, the spreading ridge jumped southward at 25 $\mathrm{Ma}$, and the spreading appears to propagate from northeast to southwest, triggering the opening of the SWSB. Li et al. [23] studied the high resolution multi-beam morphotectonics in the ESB, and pointed out the ESB experienced NWSE oriented spreading in a late period from its original N-S orientation, similar to the spreading direction in the SWSB, and further proved the SWSB and the ESB had experienced spreading in the same direction since the Miocene. (2) Yao and colleagues $[19,24]$ believed the SWSB and the NWSB experienced NW-SE trending continental rifting together with the northern margin of the South China Sea in Eocene, then began to undergo seafloor spreading. The ESB began seafloor spreading after the SWSB, and a N-S oriented strike slip fault along $116^{\circ} \mathrm{E}$ separates these two subbasins.

Magma activities in the SCS deep basin did not stop after seafloor spreading, and numerous sea mounts are distributed along the relic spreading ridge and the northern part of the oceanic basin $[16,17,23,25,26]$. The results of chronological analysis of basalts obtained from seamount dredged sampling showed that the age of the seamounts is 14-3.5 Ma [14]. A recent study has also shown the age of basalts obtained by dredged sampling near the SWSB spreading ridge is between 9.1-10.0 Ma [27]. Compared with the ESB, a lot of late volcanic magmatism occurred in the ESB after sea floor spreading, especially along the spreading ridge between $15^{\circ}$ to $17^{\circ} \mathrm{N}$, which formed a serious of seamounts including Huangyan-Zhenbei Seamount Chain, Xianbei Seamount, Xiannan Seamount, and Shixing Seamount, and contributed to the difficult terrain and large scale seamount chains in the ESB. The relatively few seamounts in the SWSB are mainly distributed along the relic spreading ridge and some local region of the northeastern side of the basin. All of these indicate that magmatic activities in the SWSB in the late stage of expansion were obviously weaker than those in the ESB, and the spreading ridge still retains the characteristics of a central rift that are peculiar to slowspreading ridges.

The SWSB is a V-shaped triangle basin in the southwestern SCS. It propagates from NE orientation to SW orientation, changing from wide to narrow in shape. It is 600 $\mathrm{km}$ long with an area of $115000 \mathrm{~km}^{2}$ and depth between $3000-4300 \mathrm{~m}$, the deepest part in the SCS [28] (Figure 1). The whole sea floor is flat with a NE trending tectonic structure, and the spreading center is occupied by a central rift, which has very different characteristics from the ESB. The northwest continental margin of the SWSB is Xisha and Zhongsha Islands, Nansha Island is the southeast margin of the basin, and to the west, the ridge propagates into the East Vietnam continental margin.

Huchon et al. [1] did some research on the rift basin in the East Vietnam continental margin based on bathymetry, seismic reflection and refraction profiles, and magnetic profiles. The basin is a typical V-shaped domain, narrow to the west. This domain is limited by a $\mathrm{N} 55^{\circ} \mathrm{E}$ bathymetric trend to the southeast and a $\mathrm{N} 30^{\circ} \mathrm{E}$ trend to the northwest. The basin is controlled by horsts and with heavy sediments. The crust obviously thins along the $\mathrm{NE} 45^{\circ}$ trending spreading axis of the basin. The basin gradually widens to the west until the exit of oceanic crust. A volcanic mount developed at the continent-ocean transition zone as a result of late stage spreading, for which a K/Ar age of $4 \mathrm{Ma}$ was obtained. The rift basin developed under the propagation of continental break-up, and is related to the ridge propagation in the SWSB according to the analysis of magnetic anomalies and other previous data. However, as far as the SWSB itself, the tectonic evolution and dynamic process has not made new progress for a long time due to the lack of new geological or geophysical data. There is an especially urgent need to acquire new answers in order to lay a solid foundation for the establishment of a tectonic geodynamic model of the basin.

\section{Data set and methods}

For the purpose of studying seafloor spreading patterns and a tectonic geodynamic model of the basin, interpretation of high solution multi-beam morphotectonics and comparisons of multi-channel seismic profiles and gravity and magnetic data are involved in order to construct the detailed characteristics of tectonic deformation and spatial distribution of the basin through high resolution stereoscopic analytical methods.

In this paper, four representative multi-channel seismic profiles across the SWSB are chosen to study. Profiles SO49-22 and SO49-23 were obtained during the "Joint Sino-German SONNE 49 Cruise" in 1987; profile N10 was obtained during the "National Ocean Subject Cruise" in the charge of the Second Institute of Oceanography, SOA, in 2004; and profile NH973-1 was obtained during the "Cruise for Project SCS continental margin geodynamics" in 2009. These four multi-channel seismic profiles are arranged in equal intervals from $\mathrm{NE}$ to $\mathrm{SW}$, which effectively controls the tectonic changes, shown in Figure 2. The seismic data we acquired is SEG-D type. Pre-stack processing of these seismic data includes amplitude compensation, static correction, gain and mute analysis, predictive deconvolution, multiple attenuation, velocity analysis, residual static corrections, and frequency filtering. Post-stack deconvolution, bandpass, and coherency filtering are then applied to the stacked 


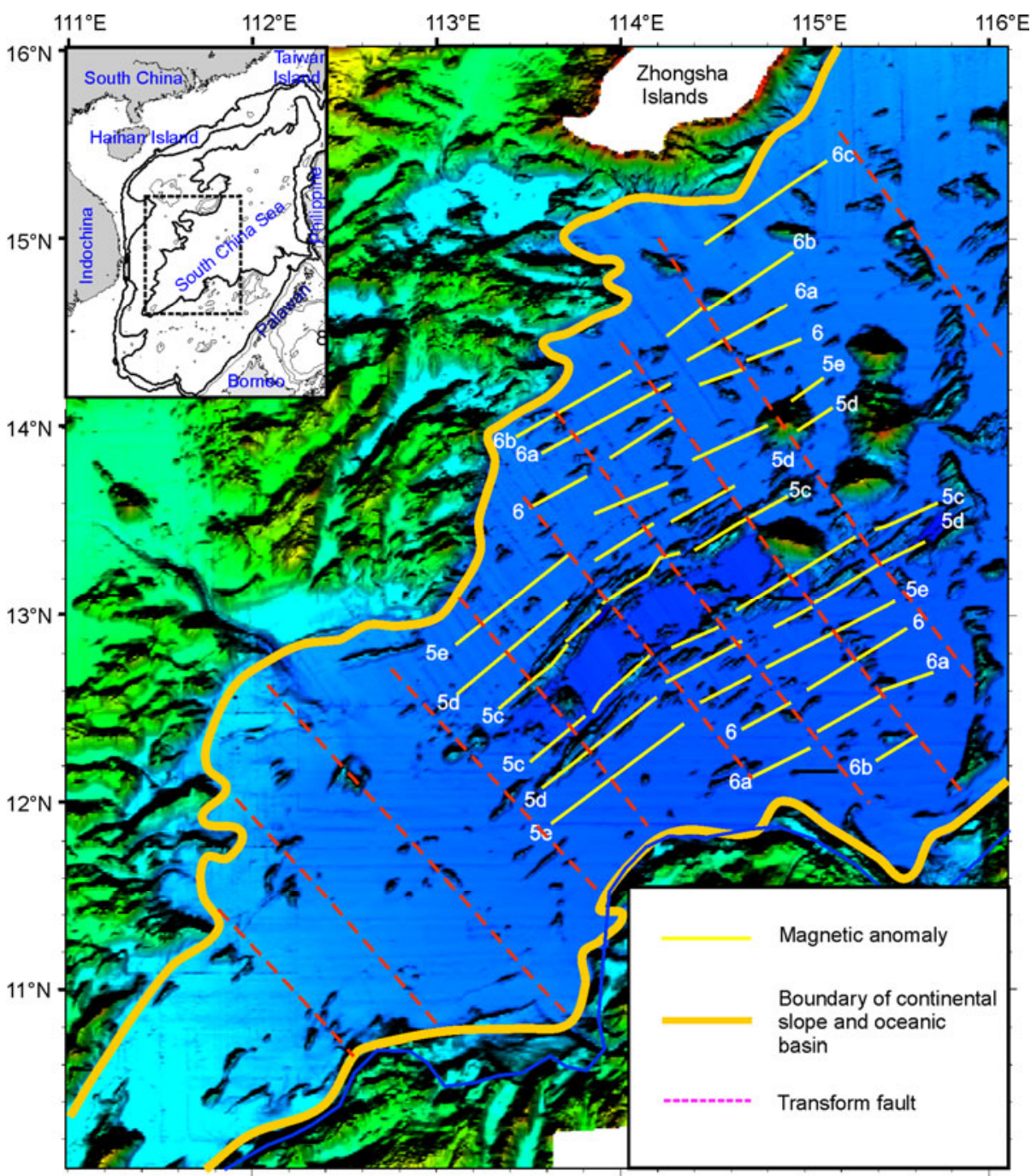

Figure 1 Multi-beam shaded relief image of the central part of the South China Sea (The shaded image is illuminated from the northeast at $45^{\circ}$ ).

data, followed by a finite-difference migration. The acquisition parameters are listed in Table 1. Detailed integrative analyses on seismic profiles revealed the tectono-stratigraphic sequences, basement fault patterns, submarine volcanic activities of the basin, and the distribution of the secondary deep depressions. A new analysis and position of the magnetic anomalies of the SWSB are reprocessed based on the new 1:500000 scale magnetic data obtained by the

Table 1 Acquisition parameters for seismic lines used in this study

\begin{tabular}{cccc}
\hline Profile & SO49-17 & N10 & NH973-1 \\
\hline R/V & SONNE & TANBAO & TANBAO \\
Acquisition date & 1987 & 2004 & 2009 \\
Streamer channel & 48 & 480 & 480 \\
Record length (s) & 12.0 & 12.0 & 12.0 \\
Sampling rate (ms) & 4 & 2 & 2 \\
Shot interval (m) & 50 & 37.5 & 37.5 \\
Airgun volume (L) & 25.6 & 83.3 & 83.3 \\
\hline
\end{tabular}

G-880/G882 cesium optically-pumped marine magnetometer, with reference to the magnetic anomalies model of Briais et al. [18].

The bathymetric data set in this area was collected with SeaBeam multi-beam system. Its working frequency is 12 $\mathrm{kHz}$. Each ping contains 151 beams with beam angles of $2^{\circ} \times 2^{\circ}$. The maximum fan angle can reach to $150^{\circ}$. For improving the quality of the data and extruding the tectonic information, we remove some records obtained during ship stopping operations and line bending, which might affect the quality of the data. Finally the data are mapped to generate shaded relief images that clearly show morphostructural features (Figure 1), which are expected to reveal the characteristics of the morphotectonics and the process of dynamic morphology, to extract surface layer information of seafloor spreading. We carry out joint interpretation of multi-beam morphotectonics and multi-channel seismic profiles in order to confirm the relationship between seafloor structure and deep structure, especially fault structure 


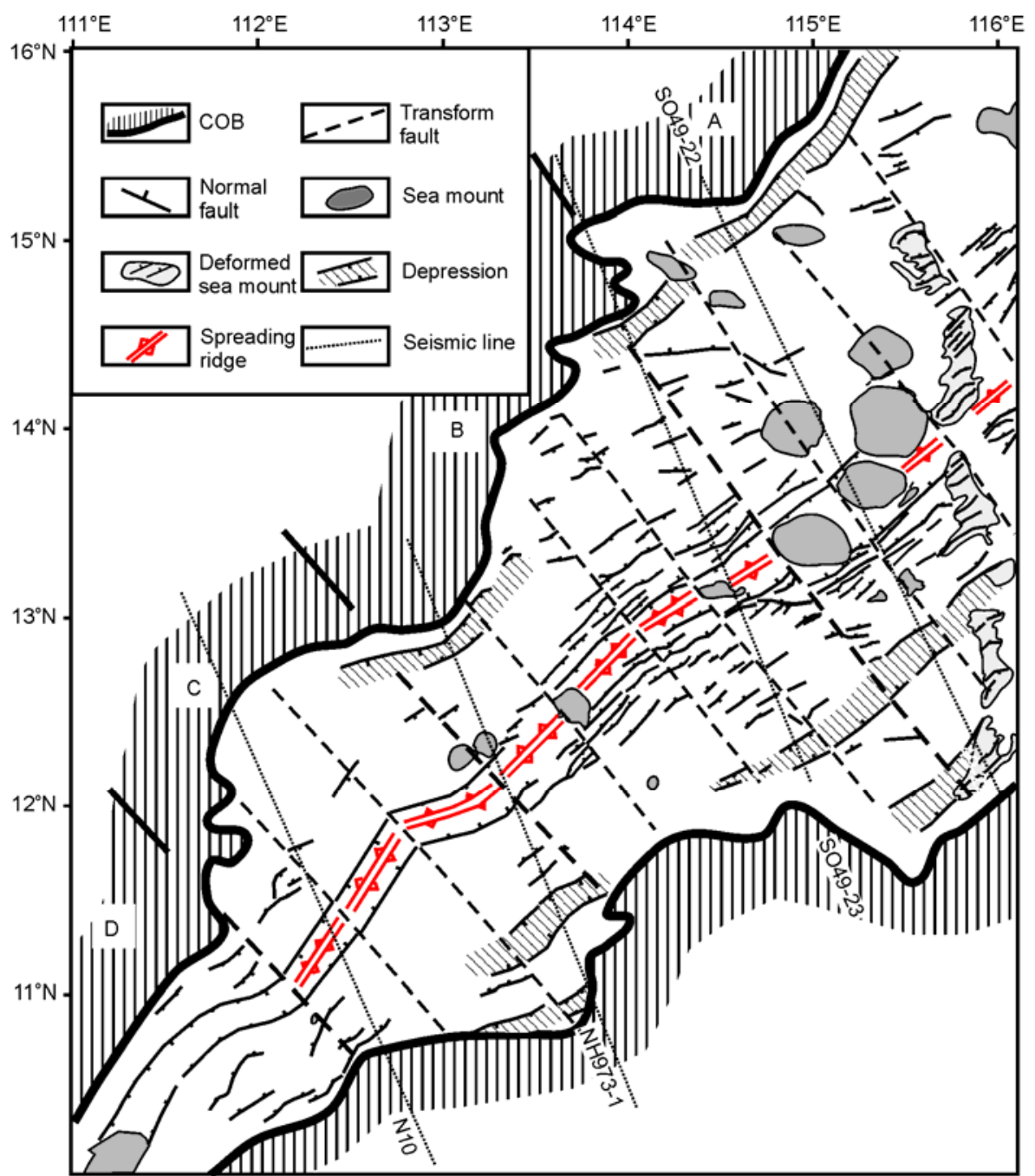

Figure 2 Linear morphostructural interpretation of multi-beam swath data of the Southwestern Subbasin, South China Sea.

combinations and spatial distribution, to deepen understanding of the mode of seafloor spreading.

\section{Analysis of tectonic dynamics}

Spatially, the SWSB has a northeastward opening trumpet shape. With respect to the amount of expansion, the northeast region is larger than the southwest one, and this kind of basin has two end-member models of seafloor spreading: one is that we assume the spreading rate of the basin is homogeneous and approximate; with this assumption the northeast region certainly spread earlier than the southwest region, which forms a model of propagating spreading from $\mathrm{NE}$ orientation to SW orientation. Another model is a shear mode for spreading. The expansion does not propagate and develop along the ridge, but occurs synchronously along the whole central ridge, that is, the opening time of the ridge is the same but with different spreading rates, which form a spreading mode with decreasing rate toward the convergent part of the basin.

\subsection{Morphotectonics and tectonic divisions}

The maps (Figures 1 and 2) of linear morphostructural interpretations of multi-beam swath data of the SWSB clearly show the whole geomorphological state of the basin. The NE-oriented central rifted graben is obvious in the SWSB which is the deepest part in the SCS. Rift shoulders are dominated by parallel fault scarps. Farther east the magma activity intensified, and formed several big seamounts. These seamounts are the result of expansion at the late stage, and the lithology is mainly composed of alkali basalts, aged 3.5 Ma [29-31], which indicates that the central rift is still a weak zone after the seafloor spreading. The central rifted graben could be divided into several sections with obviously changed orientations. The orientation of the linear basement structures beside the spreading center changes as well, generally between $\mathrm{NE} 45^{\circ}-55^{\circ}$. Seismic interpretations indicate that these linear basement structures correspond with the basement faulted blocks. The central rift has been segmented, and tectonic strike varies from segment to segment, together with the linear morphostructural interpretation, which 
represents another tectonic zone in this area, a NW oriented fault zone. These transform/strike-slip faults are distributed with similar intervals $(30-50 \mathrm{~km})$ in $\mathrm{NE} 130^{\circ}$ trending subregions and separate the NE oriented structures and even the magnetic anomalies. As mentioned previously, conjugate points on both sides of the continental margin do not mesh with one another in morphology, but present characteristics of concave-concave matching and convex- convex matching; this is very different from the conjugated model of the continental margin in the Atlantic Ocean. The seamounts in the SWSB can be divided into two kinds according to the morphology and structure features. One is a cone-shaped volcano that represents a young forming age. Off-axis seamounts also developed in the SWSB, and are mainly distributed in the northeastern part of the basin. Another type is a series of small-scale seamount groups extending from south to north, cut by NE trending faults, with breaking morphology. This might refer to an early forming age and erosion reform over a long period of time (Figures 1 and 2). The reflection seismic profiles across these seamounts reveal structures of volcanic eruption.

According to the multi-beam bathymetric map and linear morphotectonic interpretation, the SWSB can be divided into four subregions with different tectonic characteristics and evolution stages; they are Regions A, B, C, and D. Region $\mathrm{A}$ to the east features intensive magma activities. The relic spreading center is almost completely occupied by seamounts. The spreading center in Region B is a typical central rifted graben with remarkably reduced magma activities. The central rifted graben in Region $\mathrm{C}$ has been covered by abundant sediments. The basement structures are still obvious in morphology. Region D, the westernmost, behaved as a initial spreading basin, representing a transition stage from continental rifting to seafloor spreading (Figure 2). Magnetic anomaly lineations exist in Regions A, $\mathrm{B}$, and $\mathrm{C}$, but can be clearly recognized only in Regions A and $\mathrm{B}$.

\subsection{Seismic profiles and tectonic correlation}

Multi-channel seismic profiles not only indicate geological implications corresponding to multi-beam morphotectonics, but also reveal the structural characteristics of the basin and its spatial distribution (Figure 3). Sedimentary strata in the SWSB fall into post-rift sedimentary strata and synrift sedimentary strata, and a strong reflective unconformity exists between the two sequences, based on seismic facies and characteristics of sedimentary evolution. Synrift sedimentary strata are distributed mainly in local depressions that are cut by basement fault blocks. Sedimentary characteristics were mainly manifested as dustpan sedimentary structures controlled by normal faults to one side, usually destroyed by secondary normal faults; Post-rift sedimentary strata present as near-horizontal strata that cover the whole area, with stable thickness, and show a wavy distribution as the basement varies up and down, hardly disturbed by faults. From the seismic facies, the synrift sedimentary sequence is characterized by a discontinuous reflection pattern, an alternating stack of high and low energy facies, which reflects deep water turbidity sedimentary features and proximal deposit features. The post-rift sedimentary sequence shows a continuous reflecting character that represents pelagic sediments deposited in a stable energy environment. The basement of the basin is controlled by fault block tectonics. Numerous deep faults cut the basement into many different blocks resulting in the formation of a series of horst and half-horst structures, which cause the topographic fluctuations in the basement. The fault dips of the big normal faults that controlled the fault blocks mainly fall away to the spreading ridge, but there are still many fractures symmetrically distributing around some local deep depressions. This represents a lot of inhomogeneous breaking activities occurred in the spreading of the basin. Moreover, regional comparison of the seismic profiles reveals other important tectonic characteristics of the basin.

From sedimentary thicknesses and the deep depression reflected by the seismic profiles, sedimentary thickness in the basin has overall increased gradually from the spreading center to both sides of the continental margin. Although this trend character is not obvious in Profile NH973-1, and even though exceptions exist in Profile N10, this reflects the various dynamic tectonic mechanisms along the ridge. The integrated comparison of the multi-channel seismic profiles and multi-beam morphotectonics indicated that deep depressions reflecting intensive and continuous spreading exist in the basin (Figure 2). On the regional scale, these deep depressions are concentrated at both sides of the basin, 1-1.5 s thick (two-way travel time) (Figure 3), and have similar characteristics to typical spreading basins. More important, these kinds of deep depressions are not limited to both sides of the basin. We identified a relatively large, continuous sedimentary depression in the middle of the southeast side of the basin, 1.1-1.4 s thick (two-way travel time), which can also be traced on the eastern three seismic profiles (around CDP 13000 on Profile SO49-22, around CDP 1500 on Profile SO49-23, and around CDP 21000 on Profile NH973-1; Figure 3). Further analysis of the seismic profiles shows that a deep depression with local thick deposits identified in the middle of the northwest side of the basin (around CDP 1800 on Profile SO49-22, around CDP 9750 on Profile SO49-22, and around CDP 6000 on Profile NH973-1; Figure 3), is discontinuous in space and maybe cut by NW trending fractures. The distribution of the depressions indicated that the spreading of the basin was also accompanied by extension tectonics, which demonstrates the tectonic dominated spreading character of the basin.

The research on variable characteristics of deposits, magma, and tectonics of the central rifted graben indicated that the central rifted graben is representative of a NE oriented spreading center throughout the whole basin. As 

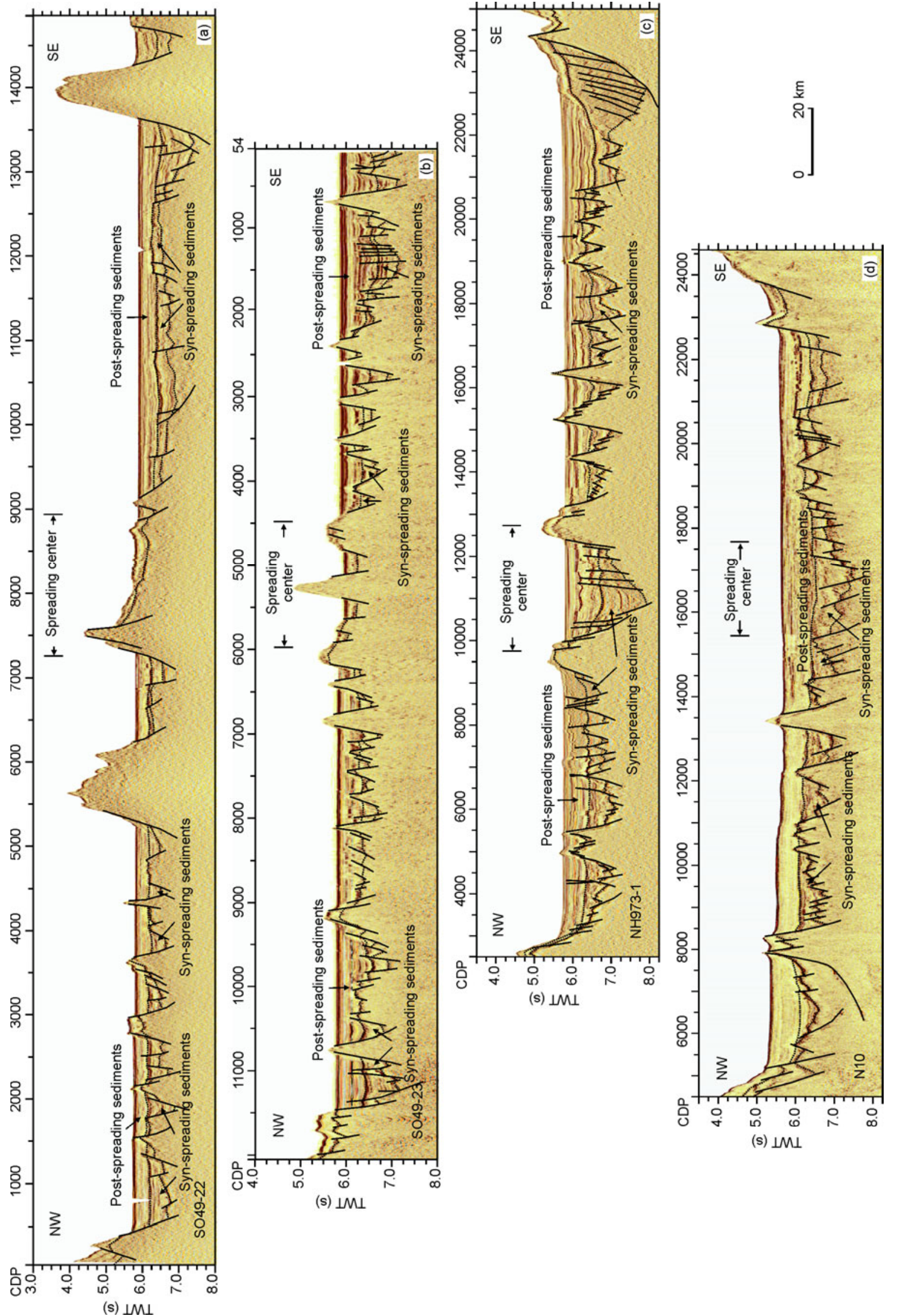

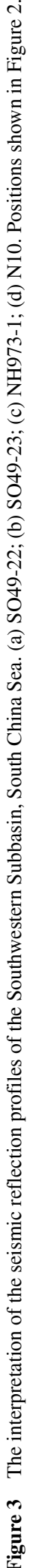


mentioned previously, the central rifted graben is characterized by segmenting; each fault cliff linear structural zone to both sides of the rift generally has a $5^{\circ}$ to $10^{\circ}$ difference in trend (independent reaches $30^{\circ}$ ) (Figure 2). Meanwhile the basement of the central rifted graben gradually uplifted from SW orientation to NE orientation, and the magma activities intensified. Seamounts are not identified on Profile N10 and Profile NH973-1 to the west. The central rifted graben (around CDP 6000-7500) is occupied by a small scale seamount shown on Profile SO49-23 to the northeast, still with rift morphology; however, the spreading center is totally occupied by seamounts on Profile SO49-22 (around CDP 7500). The thickness of the sediments in the central rifted graben decreased from $1.6 \mathrm{~s}$ in Profile N10, and $2.0 \mathrm{~s}$ in Profile NH973-1, to $0.3 \mathrm{~s}$ in Profile SO49-23 and $0.2 \mathrm{~s}$ in Profile SO49-22, presenting a decreasing trend from SW orientation to NE orientation (Figure 3). The fact that the central rifted graben in the west of the basin constitutes the biggest sedimentary center shows that the central rifted graben experienced extension and subsidence for a long time; it also reflects that material sources are mainly from the western continental margin and transported along the central rifted graben to the northeast.

\subsection{Propagation of seafloor spreading}

The new high survey-grid density magnetic survey data show that magnetic anomaly lineations are clear and have obvious characteristics, the trend can be clearly identified, and they form a spatially discontinuous distribution along the trend due to the cutting of NW oriented faults. Character recognition of magnetic anomaly lineations is carried out, especially the reposition of spatial distribution according to Briais's model, to obtain the spatial distribution pattern of the magnetic anomaly lineations. The pattern shows that the SWSB ceased seafloor spreading at 16.6 Ma (magnetic anomaly 5c), however, the age of beginning expansion decreased from NE orientation to SE orientation, 23.5 Ma in region A (anomaly 5c), 22.8 Ma in eastern region $\mathrm{B}$ (anomaly $6 \mathrm{~b}$ ), and $18.5 \mathrm{Ma}$ in western region B (anomaly 5e), representing the characteristics of ridge propagation.

We chose two NW oriented profiles, perpendicular to the trend of the magnetic anomalies, one from the east and one from the west side in the research area and used the results of a comparison of the magnetic anomalies to calculate the seafloor spreading rate of the basin. The ages of the magnetic anomalies are based on Candes and Kent [20]. Results show that the half average spreading rates to both sides of the east and west profiles are 19.09, 18.04, 16.67, and 18.00 $\mathrm{mm} / \mathrm{a}$; the half spreading rate varies between 16.67 and $19.09 \mathrm{~mm} / \mathrm{a}$, and the whole average spreading rate of the SWSB is $17.85 \mathrm{~mm} / \mathrm{a}$. Compared with the mid-ocean ridges, the SWSB belongs to a slow spreading basin. The rate of propagation along the ridge is also calculated. Because of the difficulties in identifying the magnetic anomalies in the western part of the basin, we chose the areas with clear magnetic anomalies (Regions $\mathrm{A}$ and $\mathrm{B}$ ). The beginning age of expansion is $23.5 \mathrm{Ma}$ (magnetic anomaly 6c) in eastern region $\mathrm{A}, 18.5 \mathrm{Ma}$ (magnetic anomaly $5 \mathrm{e}$ ) in the western part of region $\mathrm{B}$, and the length along the ridge is $255.6 \mathrm{~km}$; thereby the rate of ridge propagation is $51.12 \mathrm{~mm} / \mathrm{a}$. This propagating rate is comparable to many mid-ocean ridges in the world, such as the Galapagos Ridge (55.5-58.5 mm/a) [5], the Juan de Fuca Ridge (44 mm/a) [7], and the Chile Ridge, located at the joint of the Pacific Plate, Antarctic Plate, and Nazca Plate [7]. The possibility of shear spread in the basin is excluded by the parallel distribution of the magnetic anomaly lineations and mid-ocean ridges, which has further supported the tectonic model of ridge propagation.

Under the background of propagation, the spreading center gradually propagated toward a SW orientation, interacted with the continental margin in the western SCS, and finally indicated the changing tectonic mechanism from typical seafloor spreading, to initial seafloor spreading, and to continental rifting. As mentioned previously, Regions A and $\mathrm{B}$ are characterized by typical seafloor spreading. The thickness of the deposits symmetrically increases to both sides of the basin, and the magnetic anomalies are easy to identify (Profile a in Figure 4). Magnetic anomalies are also identified in Region $\mathrm{C}$, but we cannot exactly identify the age of them due to the poor characteristics. But this region has obvious tectonic features of the basement fault blocks; many deep faults cut through the basement to control the faulted sediments during the synrift stage, and the thickness of the sediments does not represent the decrease from both sides towards the spreading center, however, the spreading center became the rifted deep depression with the thickest deposits (Figure 3), which indicates that inhomogeneous expansion of oceanic crust and rifting still exist in the basin during the process of seafloor spreading and represent a stage of unsteady initial seafloor spreading (Profile $b$ in Figure 4). According to the profile from Huchon et al. [1] (Figure 5 in the referenced paper), Region D represents a rifted basin formed under the expansion and thinning of continental crust, with a complex basement morphology and intensive rifting; fault blocks and horst and graben structures are well developed in it. Oceanic crust might have been developed in the center of rifted basin (Profile $\mathrm{c}$ in Figure 4).

\section{Discussion and conclusion}

Globally, propagation of seafloor spreading in marginal sea basins usually have the following features and characteristics: (1) Propagating spreading sea basins show a V-shaped rifting and spreading and finally form typical triangle-shaped or triangle-like basins. (2) The spreading centers of propagating spreading basins are segmented and dislocated, and have changed in axial direction. (3) The age on both sides of 


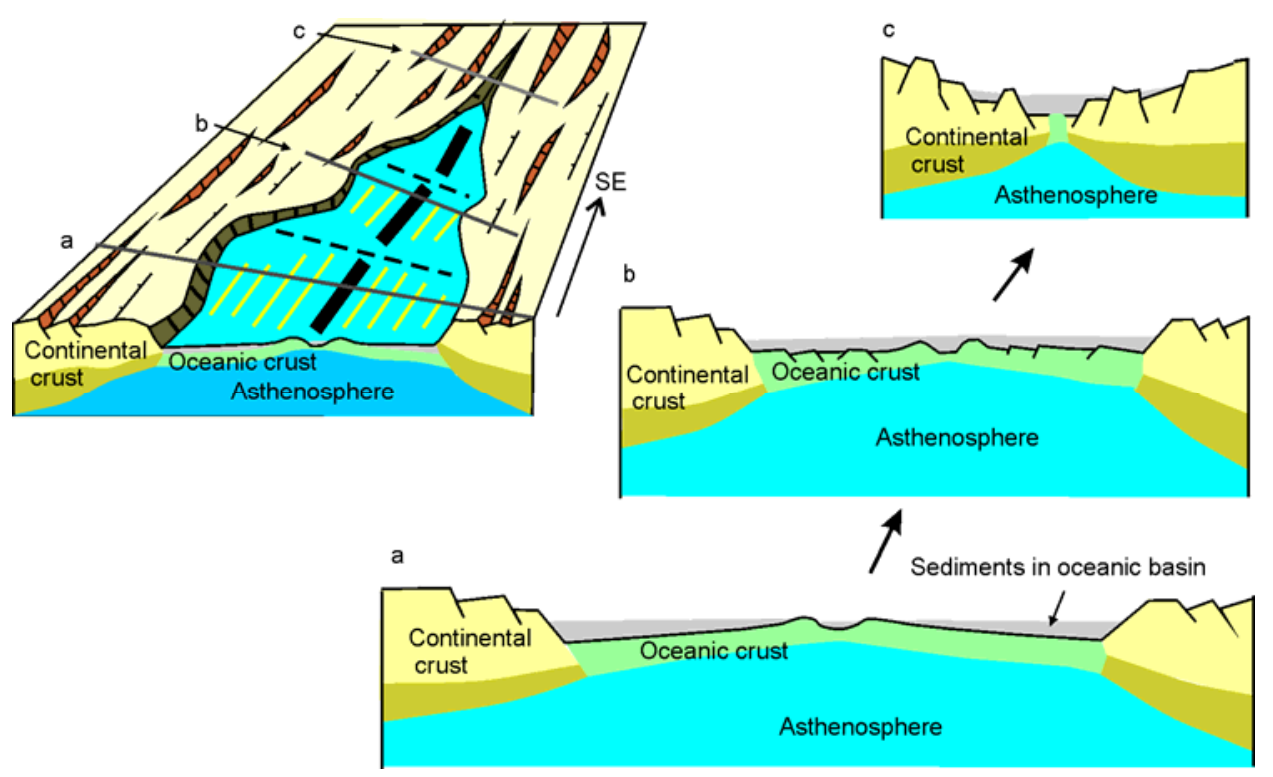

Figure 4 Map shows the propagating spreading model in the Southwestern Subbasin. Profile a shows a typical seafloor spreading with symmetrical deposits, and the thickness of the deposits increases from the spreading ridge to both sides of the basin. Profile b shows an atypical seafloor spreading with rugged bottom. The thickness of the sediments is not characterized by increasing from the spreading center to the side of the basin, and the spreading center has the maximum thickness deposits. Many deep faults that cut through the basin are developed in it. Profile c shows the initial stage of seafloor spreading, representing the rift basin thinning of the continental crust, while oceanic crust developed in the middle of the rifted basin.

the basin varies from old to young along the spreading center, while the age of the spreading axis does not change along the propagation direction. (4) Propagating spreading sea basins always consist of the continuous variable processes of seafloor spreading, ocean-continent transition, and continental rifting. (5) There is a magnetic quiet zone in the propagator of the basins, which represents the transition from seafloor spreading to continental rifting. (6) The propagation of the ridge exists in a stage with active volcanism.

The SWSB has similar characteristics to propagation of seafloor spreading, as it is formed by ridge propagation. The Gulf of Aden and Woodlark Basin in the South Pacific Ocean represent two typical types of propagation of seafloor spreading [32,33]: oceanic spreading and back-arc spreading. A comparison will be beneficial to deepen the understanding of the mechanism of tectonic evolution in the SWSB. From the tectonic patterns, the SWSB is close to the Gulf of Aden, with similar characteristics of basin shape, segments of the ridge, and the ocean-continent transition. However the Woodlark Basin has more irregular basin shape, significant segmentation of the ridge, complex continental/oceanic transition zone, and more significant temporal and spatial variation of spreading rate and propagation rate. The similarity of propagation of seafloor spreading in the Gulf of Aden, whether the SWSB has similar tectonic dynamic environment and formation mechanism or not, shows that the seafloor spreading of the SWSB is the result of westward propagation toward the western continental margin of the ESB. If this is true, the dynamic model of tectonic evolution in the SCS should be reconsidered and needs further research.
Meanwhile, the seafloor spreading in the SWSB has its own obvious characteristics, such as the inhomogeneous, continuous tectonic dynamics. The common existence of the basement faulted blocks, asymmetrical distribution of the big deep depressions, and the control of the deep faults indicated that the SWSB also stacked intensive tectonic expansion under the background of seafloor spreading, which represents a tectonic-dominated spreading that intensified from NE orientation to $\mathrm{SW}$ orientation, and it is well matched with the transition mechanism from seafloor spreading to continental rifting. Region $\mathrm{C}$, representing the initial seafloor spreading, shows double mechanisms of continental rifting and seafloor spreading. The existence of the magnetic anomaly lineations indicates the crust of this region is oceanic crust, but extension of the central rifted graben and the significant thickness of the sediments are characteristics of continental rifting (Figure 3). The stepwise transition of tectonic patterns of the seismic profiles in Region $\mathrm{C}$ indicated how the initial seafloor spreading transferred from rifted graben (Profile N10), similar to continental rifting, to regional tension of the transition stage, and how the tectonic stress transfers from central concentration to localized distribution. Finally the tectonic patterns of symmetrical seafloor spreading were identified. The research on initial seafloor spreading is the key link to understanding the relationship between continental rifting and seafloor spreading, and it is also a preferential research direction of the International Ocean Drilling Program (IODP). Because the record of initial expansion is usually located at a complex transition affected by the interaction of the ocean and the continent with poor spatial resolution, so it is diffi- 
cult to study on. The spatial distribution range of the initial seafloor spreading in the SWSB expanded because of the propagation, which formed a high resolution research region and provided an important laboratory for studying these scientific problems. So the research on the propagation of seafloor spreading in the SWSB not only improves the understanding of the tectonic dynamic mechanism of seafloor spreading in marginal sea basins, but also deepens understanding of the process of the marginal sea basins from continental rifting to initial seafloor spreading, and accordingly forms a typical research sample.

This work was supported by the National Natural Science Foundation of China (91028006) and the National Basic Research Program of China (2007CB411700).

1 Huchon P, Hguyen T N H, Chamot-Rooke N. Propagation of continatial break-up in the southwestern South China Sea. Geol Soc, 2001, 187: 31-35

2 Fumes H, Dilek Y, Skjerlie K P, et al. Variations in basaltic geochemistry along a propagating rift of late Ordovician marginal basin of the West Norwegian. Terr Nova, 1998, 10: 21-26

3 Luhr J F, Nelson S A, Allan J F, et al. Active rifting in southwestern Mexico: Manifestations of an incipient eastward spreading-ridge jump. Geology, 1985, 13: 54-57

4 Korenaga J, Hey R N. Recent dueling propagation history at the fastest spreading center, the East Pacific Rise, $26^{\circ}-32^{\circ} \mathrm{S}$. J Geophys Res, 1996, 101: 18023-18041

5 Acton G, Stein S, Joseph F. Engeln. Formation of curved seafloor fabric by changes in rift propagation velocity and spreading rateApplication to the $95.5^{\circ} \mathrm{W}$ Galapagos propagator. J Geophys Res, 1988, 93: 11845-11861

6 Wilson D S. Tectonic history of the Juan de Fuca Ridge over the last 40 million years. J Geophys Res, 1988, 93: 11863-11876

7 Morgan J P, Parmentier E M. Causes and rate-limiting mechanisms of ridge propagation: Fracture mechanics model. J Geophys Res, 1985, 90: 8603-8612

8 Tebben S F, Cande S C, Kovac L, et al. The Chile ridge: A tectonic framework. J Geophys Res, 1997, 102: 12035-12059

9 LaFemina P C, Dixon T H, Malservisi R, et al. Geodetic GPS measurements in south Iceland: Strain accumulation and partitioning in a propagating ridge system. J Geophys Res, 2005, 110: 1-21

10 Okino K, Kasuga S, Ohara Y. A new scenario of the Parece Vela Basin genesis. Mar Geophys Res, 1998, 20: 21-40

11 Benes V, Scott S D. Tectonics of rift propagation into a continental margin: Western Woodlark Basin, Papua New Guinea. J Geophys Res, 1994, 99: 4439-4455

12 Taylor B, Goodliffe A M, Martinez F. How continents break up: Insights from Papua New Guinea. J Geophys Res, 1999, 104: 74977512

13 Goodliffe A M, Taylor B, Martinez F, et al. Synchronous reorientation of the Woodlark Basin spreading center. Earth Planet Sci Lett, 1997, 146: 233-242

14 Daessle L W, Cronan D S, Marchig V, et al. Hydrothermal sedimentation adjacent to the propagating Valu Fa Ridge, Lau Basin, SW Pa- cific. Mar Geol, 2000, 162: 479-500

15 Manighetti I, Tapponnier P, Courtillot V, et al. Propagation of rifting along the Arabia-Somalia plate boundary: The Gulfs of Aden and Tadjoura. J Geophys Res, 1997, 102: 2681-2710

16 Taylor B, Hayes D E. The tectonic evolution of the South China Sea. In: Hayes D E, ed. The Tectonic and Geologic Evolution of the Southeast Asian Seas and Islands. Part 1. Geophys Monogr Washington D C AGU, 1980, 23: 89-104

17 Taylor B, Hayes D E. Origin and history of the South China Sea basin. In: Hayes D E, ed. The Tectonic and Geologic Evolution of the Southeast Asian Seas and Islands: Part 2. Geophys Monogr Washington D C, AGU, 1983, 27: 23-56

18 Briais A, Patriat P, Tapponnier P. Updated interpretation of magnetic anomalies an seafloor spreading stages in the South China Sea: Implications for the tertiary tectonics of southeast asia. J Geophys Res, 1993, 98: 6299-6328

19 Yao B C, Zeng W J, Hayes D E, et al. The Geological Menoir of South China Sea Surveyed Jointly by China and USA (in Chinese). Wuhan: China University of Geosciences Press, 1994

20 Candes S C, Kent D V. Revised calibration of the geomagnetic polarity timescale for the late cretaceous and cenozoic. J Geophys Res, 1995, 100: 6093-6095

21 Ru K, Pigott J D. Episodic rifting and subsidence in the South China Sea. AAPG Bull, 1986, 79: 1115-1136

22 Lue W Z. The characteristics of magmetic anomalies and its tectonic significance in central basin of South China Sea (in Chinese). Acta Oceanol Sin, 1987, 9: 69-78

23 Li J B, Jin X L, Gao J Y. Morpho-tectonic study on late-stage spreading of the Eastern Subbasin of South China Sea (in Chinese). Sci China Ser D-Earth Sci, 2002, 32: 239-248

24 Yao B C. Seafloor spreading and its tectonic significances of the Southwest Subbasin, South China Sea (in Chinese). Geol Res South China Sea, 1997, 9: 20-36

25 Ding W W, Chen H L, Yang S F, et al. Geological and geophysical analysis of the southwestern and eastern sub basins, South China Sea. Geol J Chin Univ, 2002, 8: 268-279

26 Pautot G, Rangin C, Briais A. The axial ridge of the South China Sea: A seabeam and geophysical survey. Oceanol Acta, 1990, 13: 129143

27 Yan P, Deng H, Liu H L, et al. The temporal and spatial distribution of volcanism in the South China Sea region. J Asian Earth Sci, 2006, 27: 647-659

28 Li J B. Evolution of Basins of Chinese Marginal Seas and Resources Effect (in Chinese). Beijing: Ocean Press, 2008

29 Wang Y J, Han X Q, Luo Z H, et al. Late Miocene magmatism and Evolution of Zhenbei-Huangyan Seamount in the South China Sea: Evidence from petrochemistry and chronology (in Chinese). Acta Oceanol Sin, 2009, 31: 93-102

30 Tu K, Flower M F J, Carlson R W. Magmatism in the south china basin. In: Isotopic and trace-element evidence for an endogenous dupal mantle component. Chem Geol, 1992, 97: 47-63

31 Yang S Y, Fang N Q, Yang S X, et al. A Further discussion on formation background and tectonic constraints of igneous rocks in central subbasin of the South China Sea. Earth Sci, 2011, 36: 455-470

32 Dauteuil O, Huchon P, Quemeneur F, et al. Propagation of an oblique spreading center: The western Gulf of Aden. Tectonophysics, 2001, 332: 423-442

33 Goodliffe A M, Taylor B, Martinez F, et al. Synchronous reorientation of the Woodlark Basin Spreading Center. Earth Planet Sci Lett, 1997, 146: 233-242

Open Access This article is distributed under the terms of the Creative Commons Attribution License which permits any use, distribution, and reproduction in any medium, provided the original author(s) and source are credited. 